\title{
DISCUSSION
}

\section{Vibro-replacement for industrial plant on reclaimed land, Bahrain}

\author{
D. G. RENTON-ROSE, G. C. BUNCE and D. W. FINLAY (2000). Géotechnique 50, No. 6, 727-737
}

\section{A. Baker, Balfour Beatty Major Projects}

In 1991/1992 Dutco Balfour Beatty carried out both the design and the construction of the civil works for the Jebel Ali $\mathrm{G}$ gas turbine and multistage flash desalination station in Dubai. Vibro-compaction was used to densify loose calcareous sand in the power island area. Rather than use zone load testing, acceptance criteria for the ground improvement were based on static cone penetrometer tests (CPT) using a defined minimum cone resistance as a function of depth, corresponding to a minimum relative density. For certain discrete layers it proved impossible to meet the minimum cone resistance criteria. The CPT results showed that these layers had high friction ratios of 3 to 4 , which would normally indicate clay. Clay layers were not expected in this environment, however, and had not been identified in boreholes. Fortunately, a nearby deep open excavation for the cooling water pumping station revealed that these zones were actually deposits consisting almost entirely of shells. High friction ratios result in these materials because the reduction in cone resistance due to crushing is far more marked than the reduction in the friction on the penetrometer sleeve. The ground improvement was therefore accepted and has performed well.

Another important observation relates to the pre-densification ground investigation. Standard penetration tests (SPTs) carried out in shell and auger boreholes did not provide results compatible with CPT results. This was despite extremely careful execution and supervision of the shell and auger boring, following all the rules such as use of an undersize shell, slow withdrawal of the shell, and keeping the water level topped up. Compatible results could only be achieved using smaller-diameter boring with mud flush sup- port. The lesson is to be cautious of using standard penetration tests in shell and auger boreholes to determine that ground improvement is required. Without other more reliable data such as static cone penetrometer testing, ground improvement could be implemented unnecessarily.

\section{Authors' response}

It is interesting to note Mr Baker's observations of zones of high CPT friction ratio in loose calcareous sand, improved by vibro-compaction, which were subsequently proven to be shell layers rather than cohesive soils, as might have been expected. Since we were aware of certain restrictions on the application of accepted soil classifications based on friction ratio in calcareous soils, only tip resistance was used as a quality control measure on the ALBA site.

Where low $q_{\mathrm{c}}$ values were recorded, further investigation by wash boring techniques was carried out to determine whether they were related to predominantly shell layers that had not consolidated after placement, or to soft cohesive soils. Sampling within an SPT split spoon, to enable recovery, proved the presence of calcareous silt. Low $q_{\mathrm{c}}$ values were recorded at various locations across the site. In areas improved by vibro-replacement, low $q_{\mathrm{c}}$ values were recorded both prior to treatment ( 7 to 8 months after fill placement) and shortly after improvement, although only at the interface of the former sea bed and overlying fill. It was therefore concluded that localised pockets of silt had become trapped during the hydraulic filling process. Fortunately, these pockets were of limited extent in plan and typically $<200 \mathrm{~mm}$ thick, as well as being generally outside settlement sensitive areas. Consequently, it was considered unnecessary to carry out additional improvement in these areas. 